\title{
On the Development Scale of Chinese Ordinary Universities
}

\author{
Cai Yujie \\ School of Economics \\ Central University of Finance and Economics \\ 39 Xueyuan South Road, \\ Beijing, NY 100081, China \\ Li Xiuyu \\ Business College \\ Xinjiang Normal University \\ 100 Guanjing Road \\ Xinjiang, NY 830017, China \\ Tao Yuhong \\ Preparatory Education College \\ Xinjiang Normal University \\ 100 Guanjing Road \\ Xinjiang, NY 830017, China
}

\begin{abstract}
Since the enrollment expansion of colleges and universities in China in 1999, the average education level of the whole society has been improved, the number of graduates has been increasingandso has been the employment pressure. By analyzing the changes of the number of colleges and universities, teachers and students, this paper draws on a conclusion and analyzes the development trend of Chinese colleges and universities. Through data analysis, it is found that both the number of colleges and universities and the number of teachers are growing and the structure of professional titles is gradually becoming reasonable; the number of students is increasing annually but the growth rate is slowing down.
\end{abstract}

Key Words: General Institutions of tertiary learning; number of schools; faculty; number of students

\section{Introduction to Ordinary Colleges and Universities}

Ordinary Colleges and Universities are institutions of full-time higher education under the supervision of the Ministry of Education of the People's Republic of China or provincial administrative departments of education (including the autonomous regions, municipalities directly under the central government, etc.). The teaching task of general education is usually undertaken by the schools that implement general education (which are usually called general education schools). General education schools can be divided into general basic education schools, vocational education schools and general colleges and universities, all of which implement full-time teaching. Among them, general basic education is divided into preschool education, primary education, junior and senior high school education, including special education for children, adolescents and youth with special needs. Vocational education includes general secondary professional education, vocational high school education, technical education and higher vocational education (general higher vocational education also belongs to General Higher Education). General higher education refers to the education of "full-time" for high school graduates who have passed the national college entrance examination.

\section{Analysis of the number of ordinary colleges and Universities}

\subsection{General Data}

\subsubsection{Number of Colleges and Universities}

As shown in Figure 1, after the launch of the policy of Reform and Opening up, the number of ordinary colleges and universities in China shows a long-term growth trend, while the number was 589 in 1978 and developed up to 2560 in 2015. From 1978 to 1989 , the number of ordinary institutions of higher learning gradually increased every year; from 1990 to 2000, the number of ordinary institutions of higher learning fluctuated less, which was maintained at 1050 or so; after 2000, with the Expansion Plan of University Enrollment, the number of institutions of higher learning increased greatly every year. 
The above data show that compared with the weak education system in the early days of the People's Republic of China, China now has a relatively large and complex education system.

Figure 1.Statistical Chart of the Change Trend of the Number of Ordinary Colleges and Universities

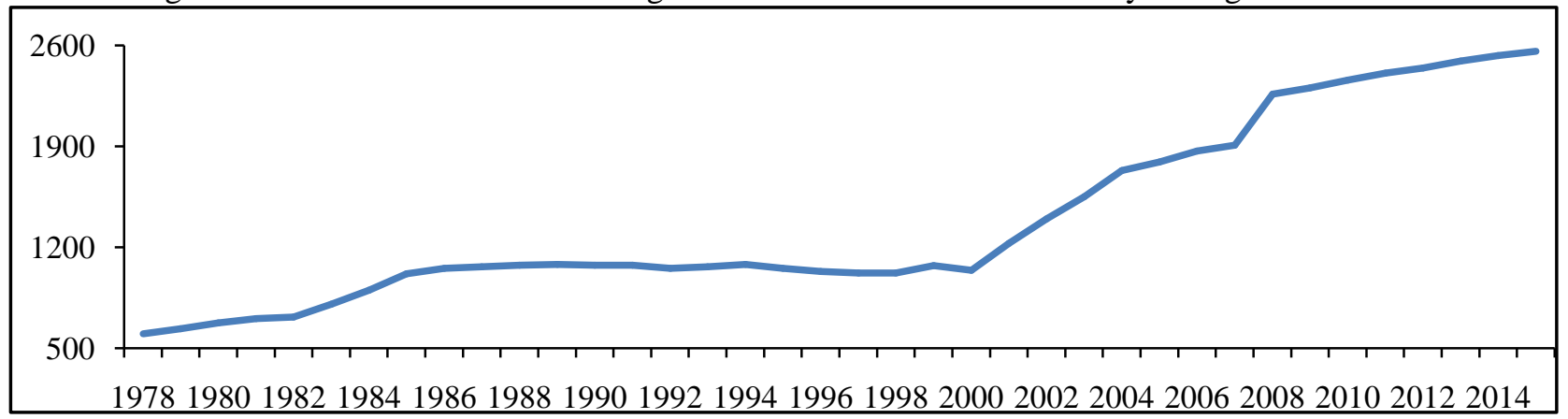

Ordinary institutions of higher learning can be divided into undergraduate institutions and colleges. As shown in Figure 2, there were 684 undergraduate colleges and universities in 2004 and 1219 in 2015, accounting for $39.51 \%$ and $47.62 \%$ of the total respectively. After 11 years of development, the number of ordinary undergraduate institutions has nearly doubled and its proportion has also increased. The number of general colleges and universities has also increased which was1047 in 2004 and increased to1341 in 2015, accounting for $60.49 \%$ and 52.38\% of the whole. Although the number of general colleges and universities increased, their proportions decreased. From 2004 to 2007, the development speed of the number of ordinary undergraduate colleges and universities was relatively slow and the number of undergraduate universities was far less than that of colleges. In 2008, the number of undergraduate universities increased significantly, which was 339 more than the previous year, accounting for $47.68 \%$ of the total, up from 38.8\% in 2007. From 2009 to 2015, the growth rate of the number of basic and specialized colleges and universities in China slowed down and the proportion of them remained in a relatively balanced state.

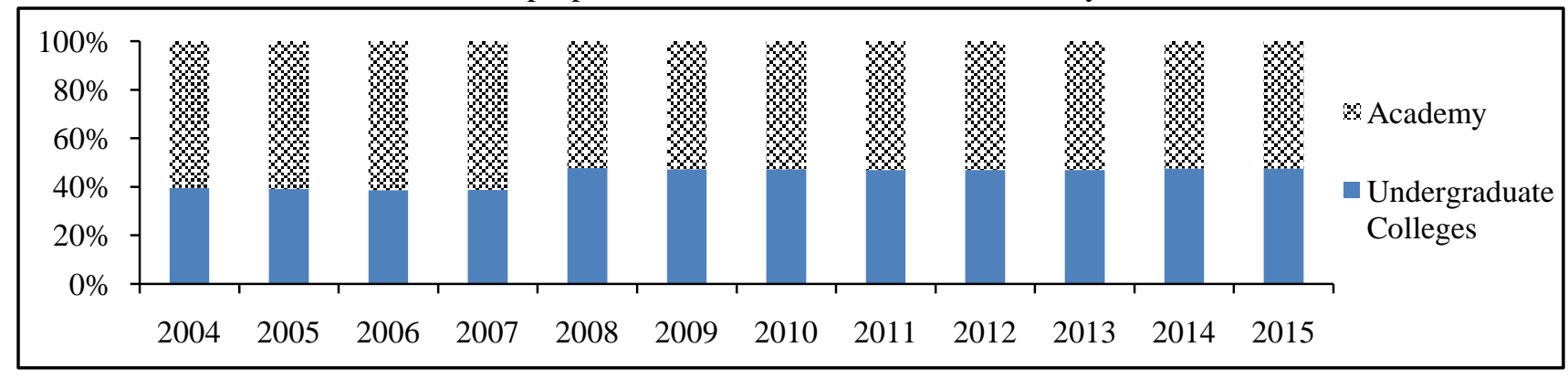

Figure 2. Statistics of the Proportion of Undergraduate Colleges and Academy

The development of science, technology and culture needs the support of talents, while ordinary colleges and universities undertake the task of training senior professional talents. Therefore, China needs to continue to increase the investment in higher education, improve the quality of teaching, increase the number of schools so that more people have the opportunity to receive higher education and to ensure the supply of talents.

\subsubsection{Number of graduate training institutions}

With the development of economy, the demand of employers for talents is higher and higher, and so is the demand of college students themselves for self-improving, the education of our college cannot meet both of the demand of talents market and its suppliers. As a result, graduate training institutions have emerged. Graduate training institutions include general higher graduate training institutions and scientific research institutions.

As shown in Figure 3, from 2004 to 2015, the number of graduate training institutions fluctuated around 790, which was 769 in 2004 and 792 in 2015. Among them, the least was 755 in 2011 and the most most 830 in 2013. In general, the number of graduate training institutions is increasing, but the change is small. From 2004 to 2006, there was almost no fluctuation. In 2007, there was an increase of 28 and then it remained at this level for three years. In 2011, there was a decrease of 42, after then it continued to increase significantly in the next two years. In 2013, it reached its peak, in 2014, the number decreased significantly, and in 2015, it began to increase. At the same time, there is a long-term increasing trend in general higher graduate training institutions, which was 454 in 2004 and 575 in 2015 . The number of graduate training institutions in scientific research institutions shows a decreasing trend, with 315 in 2004 and 217 in 2015, which was a decrease of nearly one third. 
In 2011 and 2014, the number of graduate training institutions in scientific research institutions decreased significantly, resulting in a significant reduction in the number of graduate training institutions.

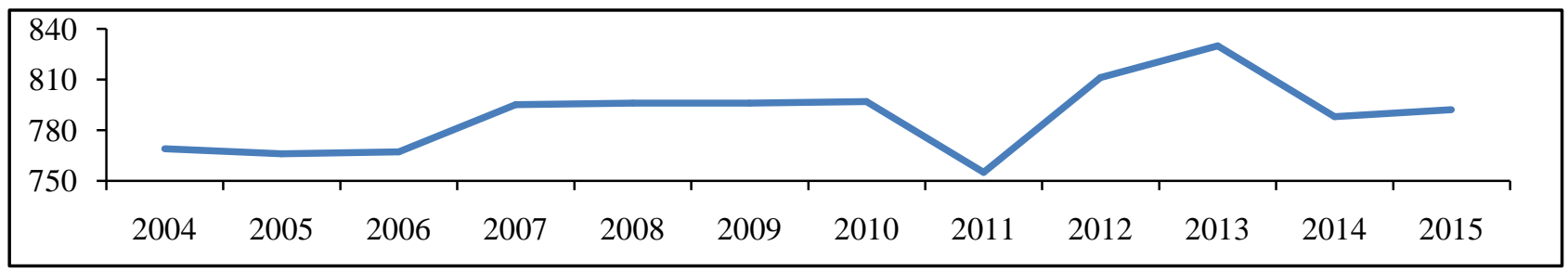

Figure 3.Statistical Chart of the Change Trend of the Number of Graduate Training Institution

\subsection{Subordinate Department Structure}

\subsubsection{College}

According to the jurisdiction departments of the colleges and universities, they can be divided into general colleges and universities under the jurisdiction of the central ministries and commissions, local governments and private general colleges and universities. From 2004 to 2014, the number of ordinary colleges and universities under the jurisdiction of the central ministries and commissions remained stable, with there were only two increases in 2012; the number of local ordinary colleges and universities increased annually but the increase was not significant, which was 1394 in 2004 and 1689 in 2014; the number of private ordinary colleges and universities increased annually, 343 in 2008, which was the direct consequence of the substantial increase of undergraduate colleges and universities in 2008. In terms of the proportion of colleges and Universities under the jurisdiction of different departments, the proportion of colleges and Universities under the jurisdiction of central ministries and commissions is stable, fluctuating up and down at the level of 5\%; the proportion of local colleges and universities decreases gradually, which decreased from $80.5 \%$ in 2004 to $66.8 \%$ in 2014; the proportion of private colleges and universities increased by nearly $15 \%$. Local undergraduate colleges and universities account for the majority of undergraduate colleges and universities, which was with a growing trend, but their proportion in undergraduate colleges and universities is shrinking. In 2004, there were 571 accounted for $83.48 \%$, and in 2014, there were 672 accounted for $55.91 \%$. Private colleges and universities have a strong momentum of development, both in terms of the absolute number and the proportion, which was 9 in 2004 accounted for $1.32 \%$, and 420 in 2014 accounted for $34.94 \%$. The number and proportion of universities under the jurisdiction of central ministries and commissions are relatively stable, there were 104 in 2004 accounted for $15.20 \%$ and 110 in 2014 accounted for $9.15 \%$.

As shown in Table 1, there were 1047 junior colleges in 2004. Among them, there are 7 colleges and Universities under the jurisdiction of central ministries and commissions, accounting for $0.67 \%$; 823 local colleges and universities, accounting for $78.61 \%$; 217 private colleges and universities, accounting for $20.73 \%$. In 2014, there were 1327 colleges, with an increase of 280. Among them, there were three colleges and universities under the jurisdiction of the central ministries and commissions, with a decrease of four; 1017 local junior colleges, with an increase of 194; 307 private junior colleges, with an increase of 90 . Generally speaking, there are many local colleges and universities, but the proportion has decreased. 
Table 1. Statistics of the Number of Colleges and Universities under the Jurisdiction of Different Departments (Unit: Institute; \%)

\begin{tabular}{|c|c|c|c|c|c|c|c|}
\hline & \multirow[t]{2}{*}{ Total number } & \multicolumn{2}{|c|}{$\begin{array}{c}\text { Under the Jurisdiction of } \\
\text { Central Ministries and } \\
\text { Commissions }\end{array}$} & \multicolumn{2}{|c|}{ Local } & \multicolumn{2}{|c|}{ Civilian-run } \\
\hline & & number & proportion & number & proportion & number & proportion \\
\hline 2004 & 1047 & 7 & 0.67 & 823 & 78.61 & 217 & 20.73 \\
\hline 2005 & 1091 & 7 & 0.64 & 861 & 78.92 & 223 & 20.44 \\
\hline 2006 & 1147 & 6 & 0.52 & 894 & 77.94 & 247 & 21.53 \\
\hline 2007 & 1168 & 5 & 0.43 & 898 & 76.88 & 265 & 22.69 \\
\hline 2008 & 1184 & 5 & 0.42 & 910 & 76.86 & 269 & 22.72 \\
\hline 2009 & 1215 & 5 & 0.41 & 924 & 76.05 & 286 & 23.54 \\
\hline 2010 & 1246 & 3 & 0.24 & 940 & 75.44 & 303 & 24.32 \\
\hline 2011 & 1280 & 3 & 0.23 & 969 & 75.70 & 308 & 24.06 \\
\hline 2012 & 1297 & 4 & 0.31 & 977 & 75.33 & 316 & 24.36 \\
\hline 2013 & 1321 & 3 & 0.23 & 993 & 75.17 & 325 & 24.60 \\
\hline 2014 & 1327 & 3 & 0.23 & 1017 & 76.64 & 307 & 23.13 \\
\hline
\end{tabular}

In contrast, the proportion of schools under local jurisdiction is decreasing, but the proportion is still large and local colleges and universities are still the main body of colleges and universities; the number of private colleges and universities has increased a lot, which shows that residents' requirements for academic qualifications are constantly improving.

\subsubsection{Graduate Training Institutions}

As shown in Table 2, the total number of graduate training institutions was 769\% in 2004, 788 in 2014 and 811 in 2012. Among them, after ten years of development, there are 85 graduate training institutions under the jurisdiction of central ministries and commissions, 369 in 2004 accounting for 47.98\%, 284 in 2014 accounting for 36.04\%; there are 99 Local graduate training institutions, 400 in 2004 accounting for 52.02\%, 499 in 2014 accounting for 63.32\%; there are no private graduate training institutions from 2004 to 2011, and the average number of them is 5 from 2012 to 2014, with little change. According to the above data analysis, the absolute number and proportion of local graduate training institutions are increasing, and local jurisdiction is also the main body that runs graduate training institutions.

Table 2. Statistics of the Number of Graduate Training Institutions under the Jurisdiction of Different Departments (Unit: Institute; \%)

\begin{tabular}{|c|c|c|c|c|c|c|c|}
\hline & \multirow[t]{2}{*}{ Total number } & \multicolumn{2}{|c|}{$\begin{array}{l}\text { Under the Jurisdiction of } \\
\text { Central Ministries and } \\
\text { Commissions }\end{array}$} & \multicolumn{2}{|c|}{ Local } & \multicolumn{2}{|c|}{ Civilian-run } \\
\hline & & number & proportion & number & proportion & number & proportion \\
\hline 2004 & 769 & 369 & 47.98 & 400 & 52.02 & & \\
\hline 2005 & 766 & 370 & 48.3 & 396 & 51.7 & & \\
\hline 2006 & 767 & 371 & 48.37 & 396 & 51.63 & & \\
\hline 2007 & 795 & 371 & 46.67 & 424 & 53.33 & & \\
\hline 2008 & 796 & 374 & 46.98 & 422 & 53.02 & & \\
\hline 2009 & 796 & 373 & 46.86 & 423 & 53.14 & & \\
\hline 2010 & 797 & 374 & 46.93 & 423 & 53.07 & & \\
\hline 2011 & 755 & 333 & 44.11 & 422 & 55.89 & & \\
\hline 2012 & 811 & 340 & 41.92 & 466 & 57.46 & 5 & 0.62 \\
\hline 2013 & 830 & 348 & 41.93 & 477 & 57.47 & 5 & 0.60 \\
\hline 2014 & 788 & 284 & 36.04 & 499 & 63.32 & 5 & 0.63 \\
\hline
\end{tabular}




\section{Analysis of the Faculty of Ordinary Colleges and Universities}

\subsection{The Total Number}

As shown in Table3, from 2004 to 2015, the total number of teachers and workers in China's general colleges and universities increased at a relatively stable rate, 161,065,800 in 2004, 236, 932,600 in 2014, which shows an increase of 75,866,800.As shown in Table3, the total number of full-time teachers in China's general colleges and universities increased at a relatively stable rate, with 858,000 in 2004, 157,256,500 in 2015, which was an increase of 71,456,500. Analysis of the above data shows that the increasing number of full-time teachers is the main reason for the increase of the number of teaching staff. What causes the increase of full-time teachers are on the one hand, due to the expansion of university enrollment in 1999, the number of students studying in the University increases every year, and on the other hand, with the expansion of university enrollment, the number of schools increases and the demand for teachers also increases.

Table 3. Statistics of the Number of Staff and Full-time Teachers in General Colleges and Universities (Unit:Ten Thousands)

\begin{tabular}{ccccccccccccc}
\hline & $\mathbf{2 0 0 4}$ & $\mathbf{2 0 0 5}$ & $\mathbf{2 0 0 6}$ & $\mathbf{2 0 0 7}$ & $\mathbf{2 0 0 8}$ & $\mathbf{2 0 0 9}$ & $\mathbf{2 0 1 0}$ & $\mathbf{2 0 1 1}$ & $\mathbf{2 0 1 2}$ & $\mathbf{2 0 1 3}$ & $\mathbf{2 0 1 4}$ & $\mathbf{2 0 1 5}$ \\
\hline $\begin{array}{c}\text { Teaching } \\
\begin{array}{c}\text { Staff } \\
\text { Full-time } \\
\text { Teacher }\end{array}\end{array}$ & 161.0658 & 174.2073 & 187.2601 & 197.4526 & 205.1029 & 211.1451 & 215.6601 & 220.4819 & 225.4372 & 229.6262 & 233.5723 & 236.9326 \\
\hline
\end{tabular}

\subsection{Title Structure}

As shown in Table4, with the expansion of the full-time faculty, the faculty strength is also increasing. The proportion of full-time teachers without professional titles increased, which was $7.06 \%$ in $2006,9.43 \%$ in 2015 , and $2.37 \%$ in 2015; the proportion of full-time teachers with primary professional titles decreased, which was $23.95 \%$ in 2006 , $19.18 \%$ in 2015 , and $4.77 \%$ in 2015 ; the proportion of full-time teachers with intermediate professional titles, deputy senior and senior professional titles all increased, and the proportion of full-time teachers with intermediate professional titles increased the most, which was 35.22\% in 2006, 62.76\% in 2015, which means a big leap of $27.54 \%$.

Table 4. Statistics of Proportion of Full-time Teachers with Professional Titles at all Levels in General Colleges and Universities (Unit:\%)

\begin{tabular}{ccccccccccc}
\hline & $\mathbf{2 0 0 6}$ & $\mathbf{2 0 0 7}$ & $\mathbf{2 0 0 8}$ & $\mathbf{2 0 0 9}$ & $\mathbf{2 0 1 0}$ & $\mathbf{2 0 1 1}$ & $\mathbf{2 0 1 2}$ & $\mathbf{2 0 1 3}$ & $\mathbf{2 0 1 4}$ & $\mathbf{2 0 1 5}$ \\
\hline Positive Height & 10.89 & 11.97 & 12.90 & 13.82 & 14.86 & 15.97 & 16.94 & 18.15 & 18.91 & 19.60 \\
Deputy Senior & 30.48 & 32.63 & 34.27 & 36.07 & 37.72 & 39.47 & 41.27 & 43.24 & 44.86 & 46.28 \\
$\quad$ Ranks & & & & & & & & & & \\
Intermediate & 35.22 & 39.44 & 43.56 & 47.75 & 51.69 & 54.99 & 57.60 & 59.70 & 61.37 & 62.76 \\
$\quad$ Primary & 23.95 & 25.70 & 25.83 & 24.80 & 23.11 & 21.84 & 20.98 & 20.37 & 19.58 & 19.18 \\
No Title & 7.06 & 7.09 & 7.18 & 7.09 & 6.93 & 6.99 & 7.24 & 8.23 & 8.73 & 9.43 \\
\hline
\end{tabular}

\section{An Analysis of the Number of Students in Colleges and Universities}

\subsection{Enrollment}

In 1978, China's general institutions of higher learning enrolled 402,000 students, and in 1979, 275,000, which showed a decrease of 127,000 , with an increase rate of $-31.59 \%$. After the end of the Cultural Revolution, the number of senior high school graduates which had accumulated for ten years reached 5.7 million in that year. There were many scenes such as father and son or teachers and students took the same exam, but only 270,000 were admitted in that year. In the following 20 years up to 1999, the number of students increased or decreased, but the fluctuation range was relatively small. Generally speaking, the number of students increased and the growth rate fluctuated greatly. In 1999, with the expansion of university enrollment, the number of students in that year increased sharply, with the growth rate reaching the maximum value from 1978 to 2015. In 2015, the number of students increased every year and the growth rate dropped to the lowest value in the time span from 1999 and 2015 in 2008 and then kept a slow decline.

The number of undergraduate students in China's general colleges and universities increases year by year, but the growth rate shows a downward trend. In 1998,there were 653,135 college students, which showed an increase rate of 43.41\%; in 2015, the total students number was 3,894,148, which was an increase rate of $1.57 \%$. College Students' enrollment expansion has an important influence on the improvement of national quality, but it can't be expanded 
blindly, so the decline of enrollment growth rate is a normal phenomenon, which realizes the selection of talents on the basis of enrollment expansion.

Except for the decline of students' size in 2007 and 2012, which were 2,838,200 and 3,147,800 respectively, the enrollment of junior colleges has been increasing every year, but the growth rate shows a decreasing trend after 2000. In some years, the impact of changes in the number of junior colleges even shows a negative growth rate. The number of college students and undergraduate students has kept a relatively balanced state, which shows that China not only attaches importance to undergraduate education, but also to college education.

In 1998, the number of undergraduate students and college students accounted for $60.27 \%$ and $39.73 \%$ respectively. The number of undergraduate students in general colleges and universities was higher than that of college students. In 2015 , the number of undergraduate enrollment in colleges and universities accounted for $52.78 \%$, which was a decrease of $7.49 \%$; in 2015, the number of college enrollment in colleges and universities accounted for $47.22 \%$, which was an increase of $7.94 \%$.

Since 1999, the proportion of undergraduate enrollment and college enrollment has fluctuated up and down, but it has been kept in a relatively balanced state without significant changes

After the resumption of graduate enrollment in 1978, the number of graduate enrollment shows an increasing trend, but the annual growth rate fluctuates. From 1978 to 1980, the shortage of high-level talents required by China's economic construction became increasingly prominent and the enrollment of postgraduates showed a negative growth. The implementation of the regulations of the People's Republic of China on academic places in January 1981 marked a new period of standardized, ordered and vigorous development of graduate education in China. In 1982, there were 11,100 graduate students and 645,100 in 2015. Postgraduates generally include postgraduates and doctoral students.

In 2004 273,000 postgraduate students were enrolled in 2004 and it was 310,000 in 2005, which shows an increase of 37,000 , with a growth rate of $13.57 \%$. After ten years of development, there were 570,600 postgraduate students in 2015 in China, which was an increase of 263,300 over 2005. With the rapid development of graduate education, the number of graduate students is increasing. The number of doctoral candidates is increasing, which was 53,300 in 2004 and 74,400 in 2015 respectively. The growth rate fluctuated greatly, with the lowest $2.12 \%$ in 2006 and the highest $4.29 \%$ in 2012, all of which did not exceed $5 \%$. As the highest level of higher education, the number of doctoral candidates is small.

As shown in Table 5, the number of graduate students enrolled in 2004 was 326,300, among whom 273,000 were for the master's degree, accounting for $83.67 \%$ of the total, and 53,300 were for the doctor's degree, accounting for $16.33 \%$ of the total. In 2015, 645,100 postgraduates were enrolled, among whom 570,600 were postgraduates, accounting for $88.46 \%$, which was an increase of 297,$600 ; 74,400$ were doctoral candidates , accounting for $11.54 \%$, which was an increase of 21,100 . The above data show that the number of graduate students and doctoral candidates increases steadily every year. The number of graduate students is significantly higher than that of doctoral students and the proportion is also increasing.

Table 5. Statistics of Number and Proportion of Master's Degree and Doctor's Degree in Postgraduate Enrollment (Unit: Ten Thousands;\%)

\begin{tabular}{lccccc}
\hline & \multicolumn{2}{c}{ Doctoral Students } & \multicolumn{2}{c}{ Master's Degree } & Graduate Student \\
& Number & Proportion & Number & Proportion & 32.63 \\
$\mathbf{2 0 0 4}$ & 5.33 & 16.33 & 27.30 & 83.67 & 36.48 \\
$\mathbf{2 0 0 5}$ & 5.48 & 15.02 & 31.00 & 84.98 & 39.79 \\
$\mathbf{2 0 0 6}$ & 5.60 & 14.06 & 34.20 & 85.94 & 41.86 \\
$\mathbf{2 0 0 7}$ & 5.80 & 13.86 & 36.06 & 86.14 & 44.64 \\
$\mathbf{2 0 0 8}$ & 5.98 & 13.39 & 38.67 & 86.61 & 51.10 \\
$\mathbf{2 0 0 9}$ & 6.19 & 12.12 & 44.90 & 87.88 & 53.82 \\
$\mathbf{2 0 1 0}$ & 6.38 & 11.85 & 47.44 & 88.15 & 56.02 \\
$\mathbf{2 0 1 1}$ & 6.56 & 11.70 & 49.46 & 88.30 & 58.97 \\
$\mathbf{2 0 1 2}$ & 6.84 & 11.59 & 52.13 & 88.41 & 61.14 \\
$\mathbf{2 0 1 3}$ & 7.05 & 11.53 & 54.09 & 88.47 & 62.13 \\
$\mathbf{2 0 1 4}$ & 7.26 & 11.69 & 54.87 & 88.31 & 64.51 \\
$\mathbf{2 0 1 5}$ & 7.44 & 11.54 & 57.06 & 88.46 & \\
\hline
\end{tabular}




\subsection{Number of Students in School}

The number of students in colleges and universities is increasing, but after 2000, the growth rate shows a downward trend. In 1998, there were 3.409 million students, in 2015, there were 26.253 million students, with a total increase of 22.844 million; in 2000 , the growth rate was $36.10 \%$, in $2015,3.05 \%$, which shows a decrease of $33.05 \%$. The above data show that the number of students in colleges and universities increases with the increase of enrollment, which is in positive proportion to the enrollment.

The undergraduate students in general colleges and universities show an increasing trend, while the growth rate shows a decreasing trend after 2000. In 1998, there were 2.2347 million people, 15.7668 million people in 2015 , which was an increase of 13.04238 million people; in 2000 , the growth rate was $24.80 \%$, in 2015 , the growth rate was $2.31 \%$, which means a decrease of $22.49 \%$. The above data show that the number of undergraduate students in colleges and universities increases in direct proportion to the number of enrollment and students in colleges and universities.

The overall trend of college students is increasing, but from 2009 to 2011, the growth rate is decreasing gradually. In 1998 , the total number was $1,174,100$, in $2015,10,486,100$, which shows an increase of 912,465 ; in 2000 , the growth rate was $58.71 \%$, and in $2015,4.17 \%$, which decreased $54.54 \%$.

In 1998 , undergraduate students accounted for $65.56 \%$ of the total, while in 2015 , it was $60.06 \%$, which was $5.50 \%$ lower; in 1998, college students accounted for $34.44 \%$ of the total number, in 2015 , it was $39.94 \%$, which was a $5.50 \%$ increase. The above data show that there is no obvious change in the number of students in general colleges and universities, and they maintain a relatively balanced state, but the number of undergraduate students has always been higher than that of college students.

The overall number of graduate students in school shows a growing trend. The growth rate changes by a large margin from 10,900 in 1978 to $1,911,400$ in 2015 , the total increase is of $1,900,500$. The data show that with the increase of graduate enrollment, the number of graduate students in China also increases.

The number of doctoral students in school is increasing year by year and the overall growth rate is declining. In 2004, the total number of doctoral candidates was 165,600, in 2015, 326, 700, which increased by 161,100 people; in 2004, the growth rate was $15.52 \%$, in $2015,4.48 \%$, which decreased by $11.04 \%$. As the highest degree of higher education, to optimize the scale of doctoral education and establish a dynamic adjustment mechanism of enrollment is necessary to change the doctoral education in China and improve the quality of doctoral education.

The overall trend of students with master's degree is increasing, but the growth rate is decreasing. In 2004, there were 654,300 students at master's degree, in 2015, 1, 584,700 people, which was an increase of 797, 400 people; in 2005, the growth rate was $20.33 \%$, in $2015,2.63 \%$, which decreased $17.70 \%$. According to the above data, the number of graduate students increases with the increase of enrollment.

As shown in Table 6, both master's and doctor's postgraduates are increasing, but the proportion of them changes slightly, and the proportion of master's postgraduates is much higher than that of doctor's. After the long-term expansion of doctoral education scale, it is necessary to strictly control the enrollment scale to gradually digest many achievements accumulated in the process of rapid expansion and effectively realize the transformation of graduate education development mode from focusing on scale to focusing on quality improvement. 
Table 6.Statistics of the Number and Proportion of Master's Degree and Doctor's Degree in Graduate Students (Unit: Ten Thousands; \%)

\begin{tabular}{lccccc}
\hline & \multicolumn{2}{c}{ Doctoral Students } & \multicolumn{2}{c}{ Master's Degree } & Graduate Student \\
& Number & Proportion & Number & Proportion & 81.99 \\
$\mathbf{2 0 0 4}$ & 16.56 & 20.20 & 65.43 & 79.80 & 97.86 \\
$\mathbf{2 0 0 5}$ & 19.13 & 19.55 & 78.73 & 80.45 & 110.47 \\
$\mathbf{2 0 0 6}$ & 20.80 & 18.83 & 89.66 & 81.17 & 119.50 \\
$\mathbf{2 0 0 7}$ & 22.25 & 18.62 & 97.25 & 81.38 & 128.30 \\
$\mathbf{2 0 0 8}$ & 23.66 & 18.44 & 104.64 & 81.56 & 140.49 \\
$\mathbf{2 0 0 9}$ & 24.63 & 17.53 & 115.86 & 82.47 & 153.84 \\
$\mathbf{2 0 1 0}$ & 25.90 & 16.83 & 127.95 & 83.17 & 164.58 \\
$\mathbf{2 0 1 1}$ & 27.13 & 16.48 & 137.46 & 83.52 & 171.98 \\
$\mathbf{2 0 1 2}$ & 28.38 & 16.50 & 143.60 & 83.50 & 179.40 \\
$\mathbf{2 0 1 3}$ & 29.83 & 16.63 & 149.57 & 83.37 & 184.77 \\
$\mathbf{2 0 1 4}$ & 31.27 & 16.92 & 153.50 & 83.08 & 191.14 \\
$\mathbf{2 0 1 5}$ & 32.67 & 17.09 & 158.47 & 82.91 & \\
\hline $\mathbf{4 3}$ & & & & \\
\hline
\end{tabular}

\subsection{Number of Graduates}

From 1978 to 2000, the number of college graduates fluctuated up and down, but the range was relatively small. After 2000 , the number of graduates increased year by year, but the growth rate showed a trend of increasing first and then decreasing. From 2000 to 2003, the growth rate increased from $12.06 \%$ to $40.36 \%$; while from 2004 to 2009, the growth rate dropped to $3.74 \%$; in 2010, it reached 8.34\%; from 2011 to 2015, the growth rate was almost zero.

The number of undergraduate graduates in ordinary colleges and universities shows an increasing trend and the growth rate fluctuates up and down with a large range. In 1998, there were 404,700 students in total, in 2015, there were $3,585,900$, which was an increase of 3,145,000 . In 2002, the growth rate reached the maximum — $45.46 \%$ and in 2015 , the growth rate was only $5.04 \%$.

The overall trend of college graduates is gradually increasing. Before 2002, the trend is increasing. After 2001, the trend is decreasing. From 2012 to 2014, the growth rate is less than zero. In 1998, the number of 425, 200 students increased gradually. In 2008, the number of junior colleges increased, and the number of students enrolled increased accordingly. The junior college system lasted for three years, resulting in the number of graduates increased to 3285300 in 2011. After 2011, the number of graduates has declined.

The graduates of university and college occupy half of the total respectively. In 1998, there were $48.76 \%$ of university graduates and $51.24 \%$ of college graduates. In 1999, with the expansion of college enrollment, China's higher education entered a leap-forward development process. In a short period of time, the number, scale, specialty setting and number of students in colleges and universities have increased dramatically. Higher education has gradually stepped into the stage of mass education, with an increasing number of graduates from universities and colleges, which may also provide fair competition stages and more new challenges. In 2015, undergraduate students accounted for $52.67 \%$ of the total graduates, increased by $3.91 \%$; specialty accounted for $47.33 \%$ of the total graduates, decreased by $3.91 \%$.

In 1978, at the launch of the Reform and Opening uppolicy, China's graduate enrollment system was not perfect. After more than 30 years of reform and opening up, great achievements have been made in graduate education, which has promoted the gradual improvement of graduate enrollment system. The number of graduates has reached to 551,500 in 2015, which is an increase of 551,500 over 1978.

The expansion of university enrollment brings about a rapid increase of doctoral graduates. In 2004, there were 23,400 doctoral candidates and the number was 27,700 in 2005, which is an increase of 4,200 people and an increase of $18.05 \%$; in 2015, there were 53,800 doctoral candidates, which is an increase of 26,100 people and an increase of 94.30\% compared with 2005. 
There were 127,300 doctoral graduates in 2004, and 497,700 in 2015, which is an increase of 370,400. From 2004 to 2015 , the number of graduates increased year by year but the growth rate fluctuated greatly. The growth rate reached a maximum of $21.97 \%$ in 2006 and a minimum of $3.22 \%$ in 2015 . The above data show that the system of graduate education tends to be improved.

As shown in Table 7, in 2004, there were 150,800 postgraduates, among whom 23,400 were doctors, accounting for $15.55 \% ; 127,300$ were masters, accounting for $84.45 \%$. In 2015 , there were 551,500 graduate students, which is 361,800 more than that in 2004, among whom 53,800 were doctors , and 497,700were masters which is 26,100 and 335,700 more than those in 2004. The above data show that the number of graduate students is increasing, but the proportion of doctoral students is decreasing year by year. It reflects that with the improvement of the education system, the requirements for doctoral graduate students are developing.

Table 7 Statistics of the Number and Proportion of Doctoral and Master's Graduates (Unit: Ten Thousands; \%)

\begin{tabular}{lccccc}
\hline & \multicolumn{2}{c}{ Doctoral Students } & \multicolumn{2}{c}{ Master's Degree } & Graduate Student \\
& Number & Proportion & Number & Proportion & \\
\hline $\mathbf{2 0 0 4}$ & 2.34 & 15.55 & 12.73 & 84.45 & 15.08 \\
$\mathbf{2 0 0 5}$ & 2.77 & 14.59 & 16.21 & 85.41 & 18.97 \\
$\mathbf{2 0 0 6}$ & 3.62 & 14.16 & 21.97 & 85.84 & 25.59 \\
$\mathbf{2 0 0 7}$ & 4.15 & 13.30 & 27.04 & 86.70 & 31.18 \\
$\mathbf{2 0 0 8}$ & 4.38 & 12.69 & 30.11 & 87.31 & 34.48 \\
$\mathbf{2 0 0 9}$ & 4.87 & 13.11 & 32.26 & 86.89 & 37.13 \\
$\mathbf{2 0 1 0}$ & 4.90 & 12.77 & 33.46 & 87.23 & 38.36 \\
$\mathbf{2 0 1 1}$ & 5.03 & 11.70 & 37.97 & 88.30 & 43.00 \\
$\mathbf{2 0 1 2}$ & 5.17 & 10.63 & 43.47 & 89.37 & 48.65 \\
$\mathbf{2 0 1 3}$ & 5.31 & 10.35 & 46.05 & 89.65 & 51.36 \\
$\mathbf{2 0 1 4}$ & 5.37 & 10.01 & 48.22 & 89.99 & 53.59 \\
$\mathbf{2 0 1 5}$ & 5.38 & 9.75 & 49.77 & 90.25 & 55.15 \\
\hline
\end{tabular}

\section{Conclusion}

After the founding of the People's Republic of China, the scale of ordinary colleges and universities in China has grown from small to large and the structure has changed from simple to complex. After the Reform and Opening up, China has carried out an important strategic transfer of work, which focuses on economic construction, strengthens the connection between economic work and other works, and increases the impact of economic work on other work. The economic construction can not be separated from talents, so the economic development leads to the increasing demand for both the number and the quality of talents.

\subsection{To Increase the Number of Institutions of Higher Learning}

First, the number of colleges and universities is increasing year by year and the range of undergraduate colleges and universities is relatively large, mainly private undergraduate colleges and universities.

Second, the number of graduate training institutions has not changed much, but the number of graduate training scientific research institutions has decreased, and the number of graduate training institutions in colleges and universities has increased.

The development of science, technology and culture needs the support of talents. Ordinary colleges and universities undertake the task of training senior professional talents. China needs to continue to increase the investment in higher education, improve the quality of teaching and ensure the quality of talents; the increase in the number of colleges and universities gives more people the opportunity to receive higher education and ensure the number of talents.

\subsection{The Number of Teachers Increases and the Structure of Professional Titles Tends to be Reasonable}

First, the number of teaching staff has increased year by year, with the increase of full-time teachers as the main factor. Second, the structure of the professional titles of the teaching staff has changed, and the number of teachers with intermediate professional titles, deputy senior and regular senior has increased. 
With the continuous increase in the number of ordinary colleges and universities, the number of teachers is also growing. As the backbone of training talents, teachers in colleges and universities should be selected carefully. In addition, China should establish a proper structure of teachers and should not blindly pursue higher education and waste human resources, but teachers should also be urged to continue their studies and not be complacent.

\subsection{The Number of Students Increases Annually, but Increase Slows Down}

First, since the expansion of enrollment, the number of college students has increased year by year, but the increase is gradually slowing down.

Second, although the enrollment of doctoral students has increased, it has not changed much.

With the increase of enrollment, there are more graduates. The fierce competition in the talent market requires schools to strictly control graduation. It is suggested that schools should offer some courses of career planning to guide college students to construct their own career planning.

\section{References}

Bi Dunrong, Yi Mengchun.Reality and Policy Rsponse to the Development of Higher Education in China[J]. Tsinghua University Education Research, 2014 (8)

Bao Wei.Theoretical Explanation and Expansion Mechanism of Scale Expansion of China's Higher Education [J]. Journal of education academic monthly, 2012 (8)

Bi Xianshun, Zhang Feng.Leapfrog Development of China's Higher Education since the Reform and Opening up and its Strategic Significance [J]. Education research, 2014 (11)

Borghans, L., B. Golsteyn, J. Heckman and J. Humphries. Identification Problems in Personality Psychology[J]. Personality and Individual Differences,2011(3).

David Woodhouse.Quality Improvement Through Quality Audit[J].Quality in Higher Education,2003(2).

Glewwe, P. The Relevance of Standard Estimates of Rates of Return to Schooling for Education Policy: A Critical Assessment[J].Journal of Development Economics, 1996(2).

Glewwe, P. Schools and Skills in Developing Countries: Education Policies and Socioeconmic Outcomes[J]. Journal of Economic Literature.2002(2).

Hanushek, E., L. Woessmann. The Role of Congnitive Skills in Economic Development[J].Journal of Economic Literature,2008(3).

Hanushek E., G. Schwerdt, S. Wiederhold and L. Woessmann. Returns to Skills Around the World: Evidence from PIAAC[J]. European Economic Review,2015(1).

Jin Lu, Qu Bingchun, Li Shengji. Labor Supply Effect of Minimum Wage System [J]. Taxation and Economy, 2019 (2): 44-49

Ke Xiao, Chu Zuwang. An Empirical Study on the Scale Expansion of Higher Education in China [J]. Education and Economy, 2014 (6)

Li H,Prashant L,Scott R,et al. Unequal Access to College in China: How Far Have Poor, Rural Students BeenLeft Behind?[J]. The China Quarterly,2015(1).

Liu Lin, Gong Xinshu, Li cuijin. Measurement and Empirical Analysis of Poverty Level of Urban Residents in Northwest China [J]. Journal of Population, 2011 (6): 18-26

Meschi E,Scervini F. Expansion of schooling and educational inequality in Europe: the educational Kuznets curverevisited $[\mathrm{J}]$.Gini Discussion Papers,2012(3).

Mare R D.Change and Stability in Educational Stratification[J]. American Sociological Review,1981(1).

Sun Xuepeng, song Lei. Empirical Analysis on the Determinants of China's Minimum Wage Standard and its Changes [J]. Contemporary Economic Science, 2018 (5): 117-123 + 128

Sun Yihan, Xie Jianguo, Xu Baochang. Minimum Wage Standard and Enterprise Cost plus: Evidence from Chinese Manufacturing Enterprises [J]. China Economic Issues, 2018 (6): 123-136

Tyler W,Halsey A H,Heath A F,et al.Origins and Destinations: Family,Class and Education in Modern Britain[J].Journal of Social Policy,1981(6).

Yan Fengqiao, Mao Dan.An Analysis of the Mechanism of the Scale Expansion of Higher Education in China: An Institutional Explanation [J]. Higher education research, 2013 (11) 